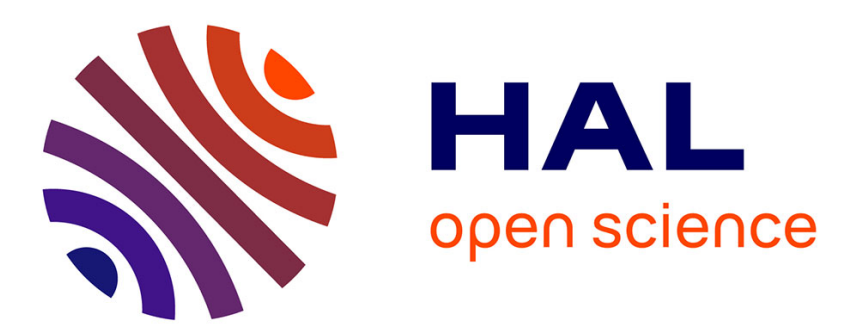

\title{
In situ measurement of the acoustic performance of a full scale tramway low height noise barrier prototype
}

A Jolibois, J Defrance, H Koreneff, P Jean, Denis Duhamel, Victor W. Sparrow

\section{- To cite this version:}

A Jolibois, J Defrance, H Koreneff, P Jean, Denis Duhamel, et al.. In situ measurement of the acoustic performance of a full scale tramway low height noise barrier prototype. Applied Acoustics, 2015, 94, pp.57-68. 10.1016/j.apacoust.2015.02.006 . hal-01266356

\section{HAL Id: hal-01266356 https://hal.science/hal-01266356}

Submitted on 2 Feb 2016

HAL is a multi-disciplinary open access archive for the deposit and dissemination of scientific research documents, whether they are published or not. The documents may come from teaching and research institutions in France or abroad, or from public or private research centers.
L'archive ouverte pluridisciplinaire HAL, est destinée au dépôt et à la diffusion de documents scientifiques de niveau recherche, publiés ou non, émanant des établissements d'enseignement et de recherche français ou étrangers, des laboratoires publics ou privés. 


\title{
In situ measurement of the acoustic performance of a full scale tramway low height noise barrier prototype
}

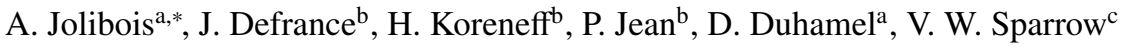 \\ ${ }^{a}$ Université Paris-Est, Laboratoire Navier, ENPC-IFSTTAR-CNRS, UMR 8205, Ecole des Ponts ParisTech, 6-8 avenue \\ Blaise Pascal, Cité Descartes, 77455 Marne-la-Vallée, France \\ ${ }^{b}$ Université Paris-Est, Centre Scientifique et Technique du Bâtiment, 24 rue Joseph Fourier, 38400 \\ Saint-Martin-d'Hères, France \\ ${ }^{c}$ The Pennsylvania State University, Graduate Program in Acoustics, 201 Applied Science Building, 16802 University \\ Park PA, USA
}

\begin{abstract}
The performance of a full scale low height barrier prototype meant to attenuate tramway noise is measured in situ. The prototype is made of a simple L-shape assembly of pressed wood boards covered on the source side with fibrous absorbing material, and has been set up temporarily in a residential area in the town of Saint-Martin-d'Hères, near Grenoble, through which a tramway line passes. A series of pass-by measurements were made at a close receiver location corresponding to the typical height of human ears, with and without the device. The tram speed has been measured as well using an auxiliary microphone located very close to the track. A significant variability in pass-by levels has been found between the different trams, even when applying an approximate correction for speed. However it is shown that the barrier provides on average an attenuation of more than $10 \mathrm{~dB}(\mathrm{~A})$, during the whole pass-by. Spectral analysis of the recorded signals is carried out as well to estimate the barrier insertion loss more accurately. Furthermore, comparisons between measurements and simplistic BEM calculations show that numerical predictions can yield rather good estimates of the actual in situ performance, within a few $\mathrm{dB}(\mathrm{A})$.
\end{abstract}

Keywords: Low height noise barrier, Tramway noise, In situ measurements, Boundary element method

\section{Introduction}

It is now well-documented that long-term exposure to noise can cause several negative health effects among which reduction of the sleep quality, harm to cognitive abilities, as well as feeling of annoyance and decrease of performance $[1,2]$. The issue of noise exposure is especially relevant in urban areas since more than half of the world population are urban dwellers, and many ground transportation noise sources coexist in such environments. Besides it seems necessary to tackle the issue of noise not only inside dwellings but also in outdoor urban areas, since according

\footnotetext{
${ }^{*}$ Corresponding author. Tel.: + 33786386521 . Fax: + 33164688938

Email address: alexandre.jolibois@enpc.fr, alexandre.jolibois@cstb.fr (A. Jolibois)
} 
to the World Health Organization, $20 \%$ of the European population is exposed to noise levels exceeding $65 \mathrm{~dB}(\mathrm{~A})$ during daytime [2], whereas the maximum recommended level in outdoor areas during daytime is $55 \mathrm{~dB}(\mathrm{~A})[3]$.

A possibility to achieve this goal is to implement compact noise barriers specifically designed for urban areas, which have received significant attention in the past decade [4-19]. This type of device should be easy to implement in a constrained environment, such as a city canyon or along a urban train track, which would typically require its height to be limited. This is why those devices have been referred to as low-height noise barriers, "low height" typically meaning less than one meter high. They could be used for instance to acoustically isolate pedestrians walking on pavements from the traffic noise coming from the street, or to reduce the noise received by cyclists riding really close to a heavy traffic driveway. Low-height barriers could even decrease noise reaching buildings, for instance in case of elevated railroads inside cities.

Previous studies on low-height noise barriers mostly used numerical modeling and scale measurements to assess the efficiency of those devices. In [4] a simple type of absorbing lowheight barrier (pedestrian restraints) meant to mitigate noise in an urban canyon was tested using scale model measurements, and provided a traffic noise reduction of $8 \mathrm{~dB}(\mathrm{~A})$ for pedestrians. Another porous traffic low-height barrier was modeled in [13] with an advanced time-domain method, and the predicted insertion loss reached $10 \mathrm{~dB}(\mathrm{~A})$ depending on the type of vehicle and receiver locations. Baulac considered a typical urban traffic noise situation and optimized the shape and the treatment (mostly absorbing) of a low-height barrier using boundary element method (BEM) simulations and genetic algorithms [7], and also showed that an insertion loss of $10 \mathrm{~dB}(\mathrm{~A})$ is achievable. Simpler shapes have also been studied with scale modeling and showed that numerical simulations were in good agreement with the BEM [6]. Koussa also studied numerically and experimentally a type of low height noise barrier made of many rocks of different sizes (gabions) [11], and the insertion loss ranged from 5 to $10 \mathrm{~dB}(\mathrm{~A})$ in this case. He also studied numerically a so-called sonic crystal low height noise barrier for tramway noise mitigation made of parallel cylinders of different diameters. Those barriers can provide up to $6 \mathrm{~dB}(\mathrm{~A})$ of attenuation by themselves, although when a rigid screen is added behind the sonic crystal the efficiency reaches $10 \mathrm{~dB}(\mathrm{~A})$, and more than $15 \mathrm{~dB}(\mathrm{~A})$ when both the cylinders and the screen are absorbent [10]. These results suggest the applicability of low-height noise barriers in urban situations. This was also confirmed by a full scale experiment in Lyon [12], in which a vegetated low-height barrier was set-up close to a urban traffic lane, and which provided about 5 $\mathrm{dB}(\mathrm{A})$ of attenuation as well as an improvement of the subjective impression of the soundscape.

Many sources of noise coexist in urban environments, including road traffic (from light and heavy vehicles), but also tramways, which has become a concern as well. Indeed, based on the fact that a tramway is an environmentally-friendly non-polluting means of transport which helps reduce the traffic congestion in city centers, there has been a renewed development of this means of transportation in the past decade, for instance in several European cities (including Paris, Brussels and London). Tramway has hence become a significant urban noise source. Back in the seventies and eighties, several studies had already reported significant levels and annoyance due to tramways [20-22]. Along with the more recent tramway development, researchers have characterized physical emission levels of tramway-induced noise and vibration [23-26] and annoyance $[24,27]$. Tramway noise is all the more problematic since pedestrians and cyclists can be close to trams on a regular basis, and because the power levels of tramway noise sources are significant (above $90 \mathrm{~dB}(\mathrm{~A})$ for typical urban speeds [26]), the noise level perceived by nearby receivers can be quite high, well above $80 \mathrm{~dB}(\mathrm{~A})$. However it has been shown that noise sources for modern tramway are mostly located close to the ground [26]. This suggests that a properly 
designed low-height noise barrier can be efficient against tramway noise, even for receivers close to the tram track. One should however point out that the noise emitted from the roof due to the HVAC (heating, ventilation and air conditioning) system mounted on certain trams, and that a low-height protection would not attenuate, is significant only at low rolling speeds [26]. This source of noise could be tackled for instance by implementation of barriers directly on the tram close to the HVAC, and will not be considered here. A few types of tramway low height barriers have already been studied [10,16-18], and it has been emphasized that in this case the multiple reflections between the barrier and tram body strongly influence the insertion loss, and therefore treating the barrier for instance with absorptive material seems critical in this context.

Nevertheless, the assessment of a noise barrier performance based on numerical calculations or scale model measurements is intrinsically biased, due to the idealization of the physical and geometrical features of a potential implementation site. For instance, in scale model measurements as well as numerical calculations, one or few ommidirectional sources are usually considered, whereas the actual noise sources of a tramway are a lot more complex due to their spatial distribution and directivity [26]. Moreover, the geometrical model of the tram itself is usually simplified and the body is assumed rigid, which is also an approximation. It is unclear how much those approximations matter for the actual performance of a low-height noise barrier. It seemed therefore necessary to actually build and set-up a full scale prototype in a real situation in order to assess what actual noise reduction performance can be obtained by such a barrier, and also to evaluate if numerical predictions and scale model measurements yield a reasonable approximation of the in situ performance.

In this work, the performance of a full scale low-height barrier prototype meant to attenuate tramway noise for nearby pedestrians is measured in situ. The design of the prototype and the choice of the implementation site are first discussed. The performed measurements are then presented and analyzed in order to evaluate in a quantitative way the noise reduction. Comparisons with simple BEM calculations are finally made to assess how close the numerically predicted performance are compared to the measured performance.

\section{Preliminary considerations}

\subsection{Choice of the implementation site}

The city of Grenoble and its nearby towns have developed in the past few years several tramway lines, which offers several options to achieve a full scale test of a tramway low height noise barrier. The choice of the implementation site for the prototype was then based essentially on a background noise consideration. Let us recall that our goal is to evaluate the performance of a low-height barrier in a realistic environment, which we will characterize by an insertion loss, that is a difference of level at a given receiver point with and without the barrier. However, this difference in level will be related to the effect of the barrier only if other surrounding sources of noise - which would not be attenuated by the barrier - do not influence the measured level too much. For this reason the background noise level of the implementation site should be sufficiently smaller than the measured level during the pass-by of a tramway, with and without the barrier. It is equivalent to state that the signal to noise ratio (SNR) should be sufficiently high, the signal referring here to the contribution of the pass-by of a tramway to the sound field, with and without the barrier, and the noise referring to the contribution of other surrounding sources in the environment.

A corollary of this consideration is that one should choose a site where the level due to the pass-by of a tramway is as high as possible, since this would enhance the SNR. This in turn 
means that the speed of the tramway at the site should also be as high as possible, since there is a strong correlation between tramway noise power levels and speed [26], as for most transportation noise sources.

Finally, for practical reasons, assembling and disassembling of the prototype and measurements had to happen within one day only. Since the prototype itself has been built at the CSTB Grenoble site, the implementation site had to be not too far away to shorten transportation time.

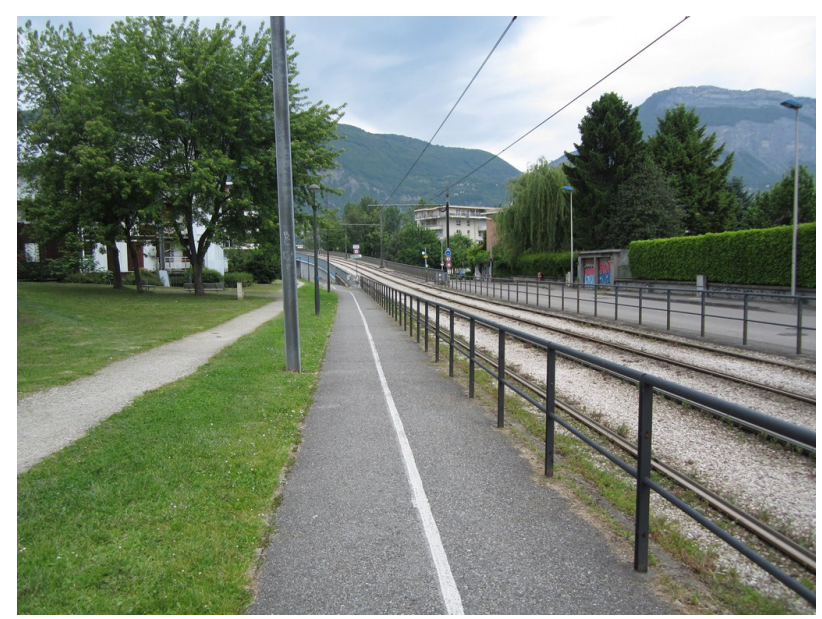

Figure 1: View of the implementation site, in Saint-Martin-d'Hères (France). The tramway tracks are those of the B line, between the stops Les Taillées - Universités and Grand Sablon. In the background the tracks run over a bridge across the Isère river. The street opposite the bike trail is Antoine Polotti street.

Based on these considerations, it has been chosen to set up the prototype on an asphalt bicycle trail running along the B line of the Grenoble tramway system, between the stops Les Taillées - Universités and Grand Sablon, opposite Antoine Polotti street in the town of Saint-Martind'Hères. A view of the site is shown in Fig. 1. The environment is relatively quiet since this site is next to a residential area, with few cars passing on Antoine Polotti street. However tram passbys are quite loud, as we will see later, due to the fact that trams roll at relativity high speeds in this area, and probably also to the type of track, as it has been shown that this has a major influence on tram noise power levels [26].

One can also notice the presence of a safety fence running along the tracks. This fence is an advantage for setting up the prototype since it will be easy to secure the installation of the noise barrier onto the fence in order to eliminate any risk of fall on the tracks. It is also believed that this safety fence has a negligible influence on the sound field.

It also turned out that inhabitants of this area have complained about noise emissions from the trams, and it therefore seems that this site would also be a good choice for installation of a long-term barrier, although this was not a requirement for the purpose of this work, which again is the evaluation of the performance of a low-height barrier prototype in a realistic environment.

\subsection{Choice of the design}

Due to time and feasibility constraints, a relatively simple design for the noise barrier prototype had to be retained. Previous studies showed however that it is essential to cover the face of the barrier directly exposed to the noise sources radiation with absorptive materials in order to 

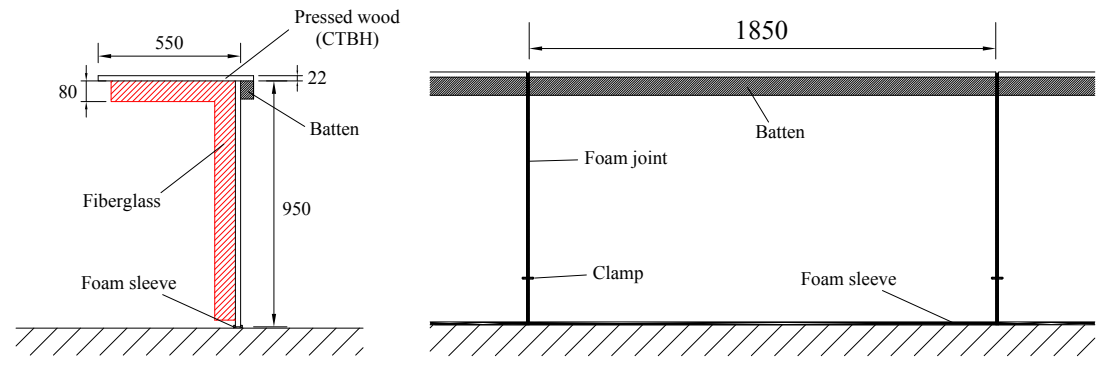

Figure 2: Schematic of the low-height barrier prototype. The barrier is made of treated pressed wood and fiberglass Left: L-shape cross section. Right: back view of one element and joint system between elements (dimensions are given in $\mathrm{mm}$ ).

attenuate the multiple reflections happening between the tramway body and the barrier [16-18]. Besides, the T-shape design has been shown to be quite efficient $[16,18]$. Therefore, a simple L-shape covered on its interior part by fiberglass is proposed (see in Fig. 2). Indeed, preliminary calculations showed that the difference between the $\mathrm{T}$ and the $\mathrm{L}$ shapes has a limited influence on the acoustic performance, however the L-shape barrier is significantly easier to handle and to transport. Besides, one can point out that if a long-term barrier was set-up, it would be necessary to consider a sustainable absorptive material or to properly package the fiberglass in order to avoid any health hazard related to its presence. However in our case, since the prototype was meant to stay in place for a few hours only, it was found unnecessary to take such precautions.

The length of the barrier also had to be limited namely for ease of transport and installation. The barrier therefore consists of 12 elements, each $1.85 \mathrm{~m}$ long, for a total length of a little more than $22 \mathrm{~m}$. Trams running on the B line are Alstom Citadis 402 trams which are $43 \mathrm{~m}$ long, and therefore the barrier covers at most half of the tramway length, as shown in Fig. 3.

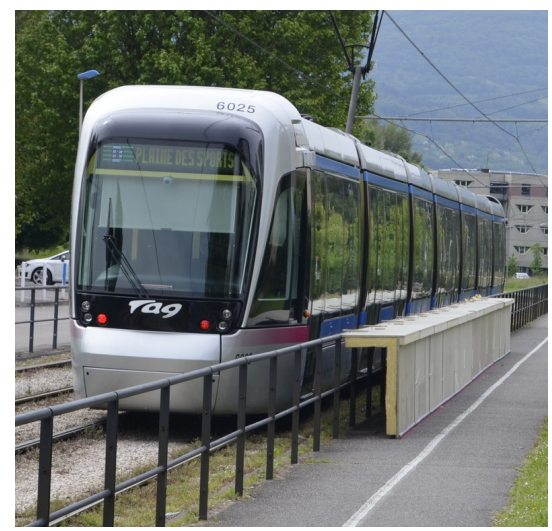

Figure 3: View of the noise barrier prototype with a Alstom Citadis 402 tramway of the Grenoble B line passing-by. The length of the barrier is about $22 \mathrm{~m}$, whereas the tram is about $43 \mathrm{~m}$ long.

Each element is made of a simple assembly of two pressed wood boards - one $60 \mathrm{~cm}$ wide, the other $95 \mathrm{~cm}$ wide - bound together to form a right angle thanks to shelf brackets and a batten. 
The boards are $22 \mathrm{~mm}$ thick, which was chosen to ensure the board to be considered acoustically rigid. Indeed, the bulk density of the pressed wood is about $\rho=700 \mathrm{~kg} / \mathrm{m}^{3}$, and based on a simple mass law criterion, the transmission loss across the board is TL $=20 \log \left(\pi \rho e f / \rho_{0} c_{0}\right)$ with $f$ the frequency of interest, $e=22 \mathrm{~mm}$ the panel thickness, $\rho_{0}=1.21 \mathrm{~kg} / \mathrm{m}^{3}$ the density of air and $c_{0}=343 \mathrm{~m} / \mathrm{s}$ the speed of sound. The frequency range of interest for tramway noise is from about $100 \mathrm{~Hz}$ to $4000 \mathrm{~Hz}$ [26], which means that according to the mass law the transmission loss remains above $20 \mathrm{~dB}$ in this range, which is sufficiently large to neglect any transmission through the board.

Each element is bound to the next via a simple joint system: a rectangular piece of dense foam is glued on the side of the pressed wood boards, and several tied plastic clamps ensure compression of the joint, thus preventing strong acoustic leaks. Similarly, an insulating foam sleeve is put at the bottom of the structure to prevent leaks at the ground level. The compression in this case naturally happens thanks to the weight of the structure. Views of the barrier cross section and joint system are shown in Fig. 4.
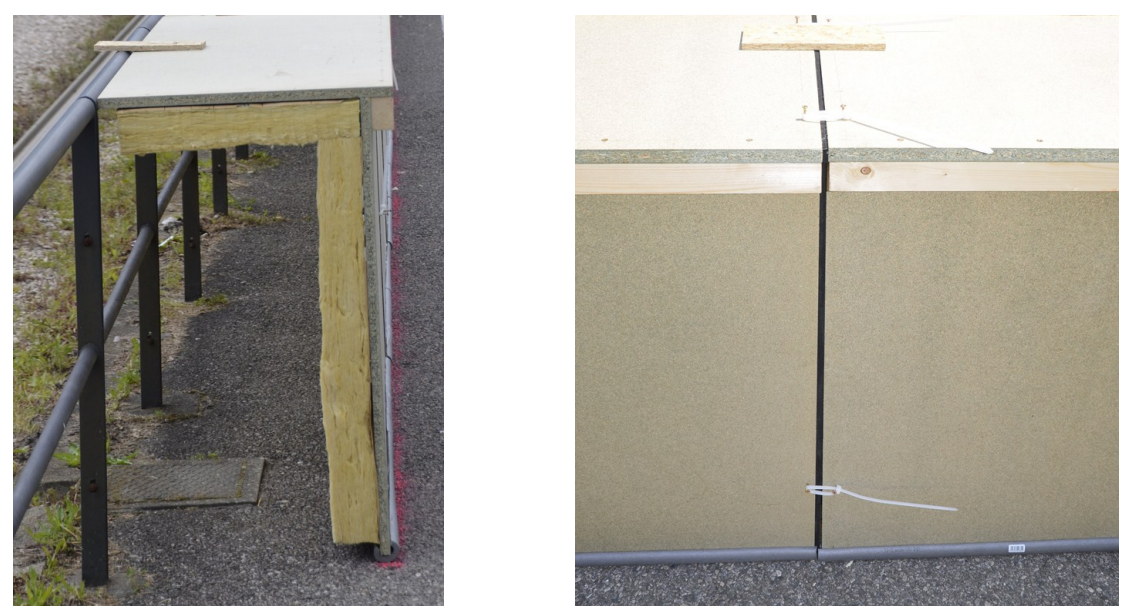

Figure 4: Views of the low-height barrier prototype. Left: cross section. Right: joint system between elements.

\section{Performed measurements}

In this work, we are interested in assessing the benefit of the presence of a low-height barrier for a close receiver, typically a pedestrian or a cyclist, while a tramway is passing by. We therefore mostly need to measure the level at a receiver point located at the typical height of human ears. Two heights have been considered: $1.5 \mathrm{~m}$, corresponding to a person standing, and $1.2 \mathrm{~m}$, corresponding to a person sitting on a bench for instance. The horizontal distance from the safety fence is $3 \mathrm{~m}$, which corresponds to a distance of about $3.5 \mathrm{~m}$ to the tramway side (see in Fig. 5). Finally the receivers are located in the vertical plane cutting the barrier in the middle of its length, which is where the noise barrier has the most important effect.

Pressure signals and levels were recorded by a B\&K sound level meter (SLM) at the receiver locations. The SLM was set up to record the pressure signal in a WAV file (sampled at $48 \mathrm{kHz}$ ) and the equivalent A-weighted levels $L_{\text {Aeq,T }}$ over successive time periods of duration $\mathrm{T}=100 \mathrm{~ms}$. Binaural measurements were also made, although this type of measurement was not exploited 


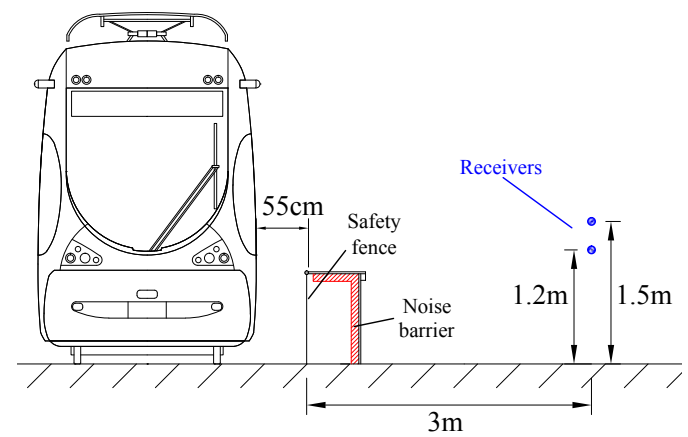

Figure 5: Cross sectional schematic showing relative positions of the tram, low-height noise barrier prototype and receivers.

in this work. Besides, we used an auxiliary microphone (embedded in a cellphone) which was placed very close to the tracks, away from the shadow zone of the barrier, and meant to record the pass-by of the train without any influence of the barrier, which would allow us to determine the speed of the tram during the pass-by (more details will be given in section 3.1 ). The different devices are shown in Fig. 6.
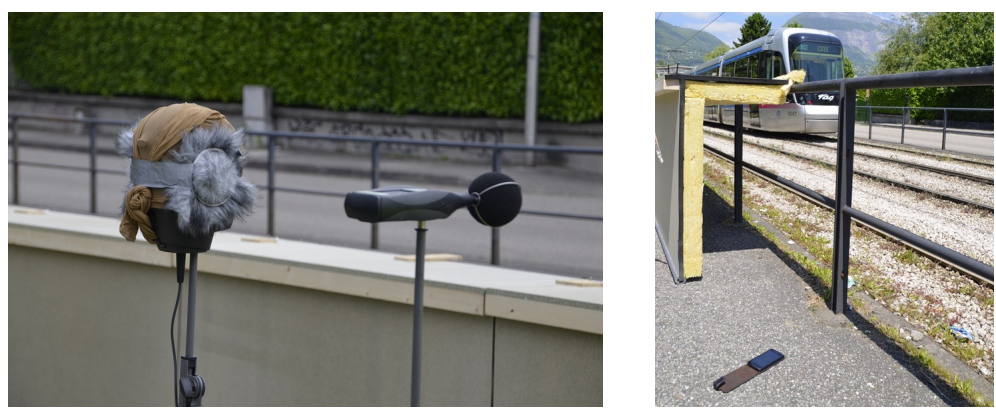

Figure 6: Devices used in the measurements. Left: B\&K type 2250 sound level meter and binaural head. Right cellphone LG P970 used as an auxiliary microphone for speed measurement.

Finally, SLM measurements are performed over a constant time interval of $15 \mathrm{~s}$, each measurement being started manually by an operator whenever a tram is approaching. Besides, measurements are done for close trams - running the closest to the barrier, going from Grand Sablon to Les Taillées - and far trams - running the opposite way, towards the bridge over the Isère river (see in Fig. 7).

We therefore have eight different configurations of measurements for which the analysis will be performed, depending on:

- Receiver height: $1.5 \mathrm{~m}$ or $1.2 \mathrm{~m}$.

- Presence of the noise barrier (we will refer to each case as with or without barrier).

- Proximity of the tram: close or far. 

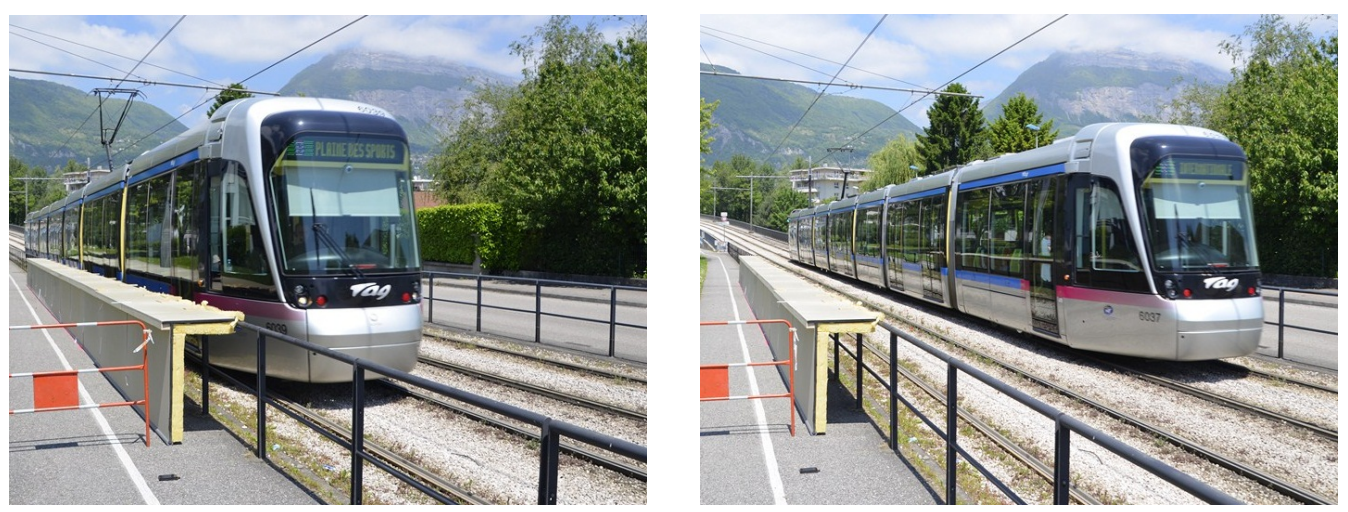

Figure 7: Views of two tram pass-bys. Left: close tram, rolling towards the foreground of the picture. Right: far tram, rolling towards the background of the picture (towards the bridge over the Isère river).

\subsection{Speed measurement from auxiliary microphone signal}
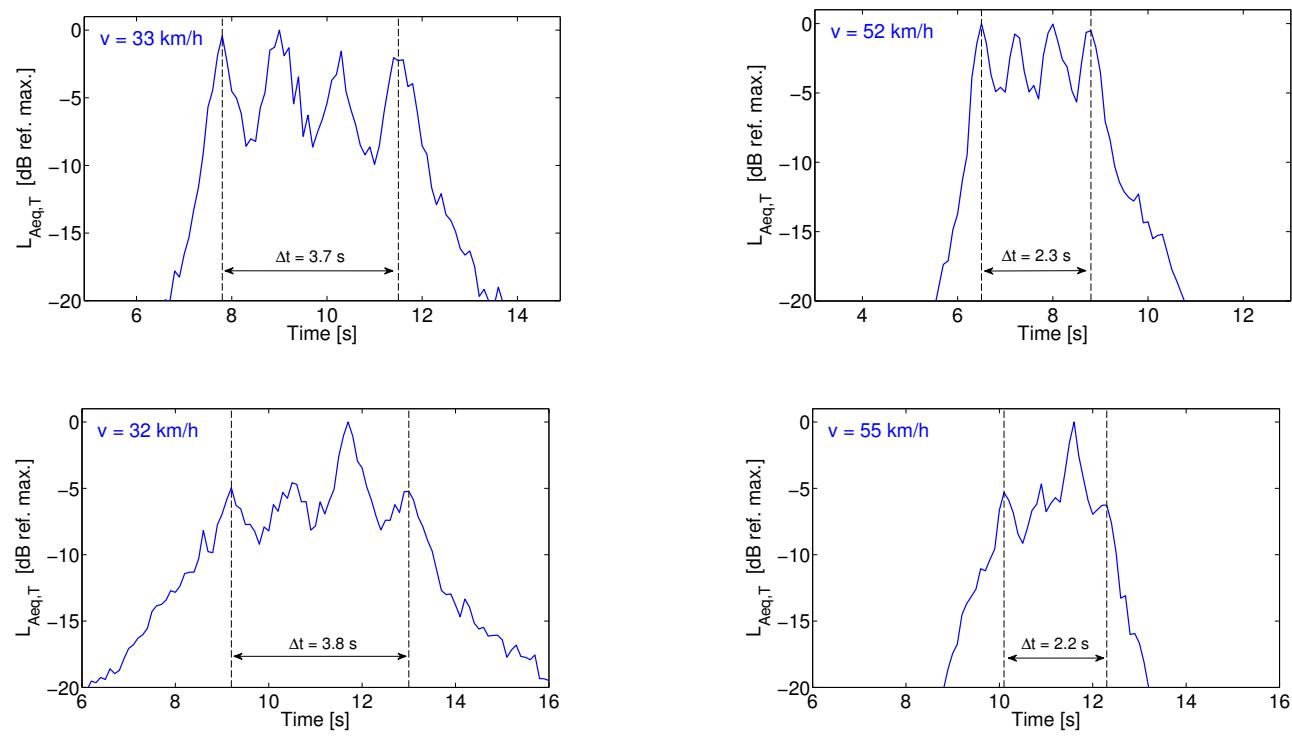

Figure 8: Examples of A-weighted levels $L_{\text {Aeq, }}$ time histories in $\mathrm{dB}(\mathrm{A})$ (referenced to the maximum value) during tram pass-bys, with $T=100 \mathrm{~ms}$, recorded with the auxiliary microphone. For each signal, the passage of the four bogies in front of the microphone is identified, which yields a time interval $\Delta t$ corresponding to the passage of the first and last bogie. From the known distance between the two extreme bogies $\left(d_{1}=33.5 \mathrm{~m}\right.$ for Citadis 402 trams, see in Fig. 9), one can estimate the speed as $v=d_{1} / \Delta t$, indicated as well on each plot. Top: close trams. Bottom: far trams.

Speed is an important parameter in pass-by levels measurements since it is highly correlated with noise sources power levels, as already pointed out. To avoid any bias in the evaluation of the noise reduction due to the barrier, as well as to study this correlation, it therefore seemed 
necessary to evaluate the speed of the tram during each measured pass-by. One approach is to determine the pass-by duration and to use the known length of the tram to calculate the speed. Durations can be measured with infrared cells, as done in [26], but one can also use the time history of the pass-by given by the $L_{\text {Aeq,T. }}$. Indeed, the passage of a bogie close to the microphone generates a bump in level which can be detected. From the knowledge of the corresponding instants, one can measure time intervals between the passage of the different bogies, and finally the speed assuming the distances between the bogies are known. However when the barrier is present, this bump is strongly attenuated, and therefore the measurement of the speed is more difficult. This is why an extra microphone was needed, located close to the tracks and away from the shadow zone of the barrier. Besides, the quality of the recording is not extremely important for this application, which is why using a simple cellphone microphone was enough.

A few examples of this process are shown in Fig. 8. From the recorded WAV file, the signal is extracted and the $L_{\text {Aeq,T }}$ calculated by applying the A filter and averaging over intervals of $100 \mathrm{~ms}$. All time histories present several bumps, corresponding to the pass-by of the bogie areas, since these sources emit more noise than the rail itself. This allows one to identify the instant at which each bogie passed in front of the microphone, which yielded the time interval $\Delta t$ between the pass-by of the first and last bogie. For the Citadis 402 tram, the bogies are separated by a distance of $11.15 \mathrm{~m}$, and therefore the distance between the first and last is $d_{1}=33.45 \mathrm{~m}$ (see in Fig. 9). Assuming the speed is constant during this interval, it can be calculated simply by $v=d_{1} / \Delta t$.

There is of course uncertainty in this measurement since the bumps might not easily identifiable (see for instance in Fig. 8 bottom plots) and since the time interval $\Delta t$ is known with a precision of $0.1 \mathrm{~s}$ only. Measured time intervals typically vary between 2.0 and $4.0 \mathrm{~s}$, hence the error varies between 2.5 and $5 \%$. This yields a precision of 1 to $3 \mathrm{~km} / \mathrm{h}$ in the speed, which for the purpose of this work is sufficient. Besides, it was found that taking a shorter averaging period made in general the identification of the bogie pass-bys more difficult.

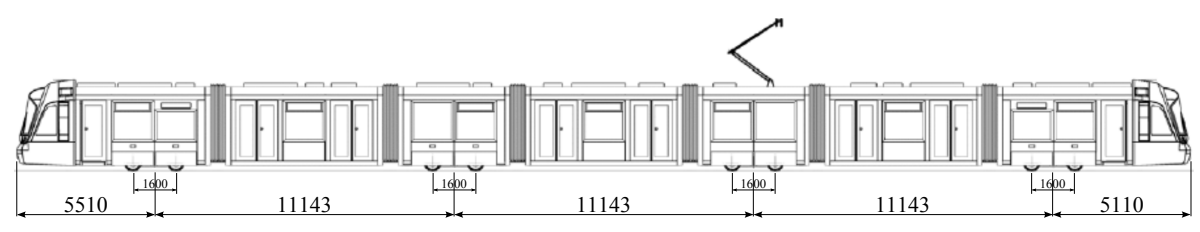

Figure 9: Longitudinal schematic of the Alstom Citadis 402 tram. Dimensions are given in mm. The distance between the first and last bogie centers is about $3 \times 11.15=33.45 \mathrm{~m}$, and the total length of the tram is about $43.65 \mathrm{~m}$.

\section{Measurement analysis and barrier effect}

In this section different analyses of the measured data are proposed in order to evaluate the effect of the low-height noise barrier prototype in terms of noise reduction: first based on the equivalent pass-by level, then on the time histories of the $L_{\mathrm{Aeq}, \mathrm{T}}$ during the pass-bys, and finally on the spectrum of the recorded signals.

\subsection{Pass-by equivalent level and speed dependence}

First the correlation between noise level and speed is studied, in each measurement configuration. The equivalent A-weighted sound pressure level is chosen to quantify the level during the 

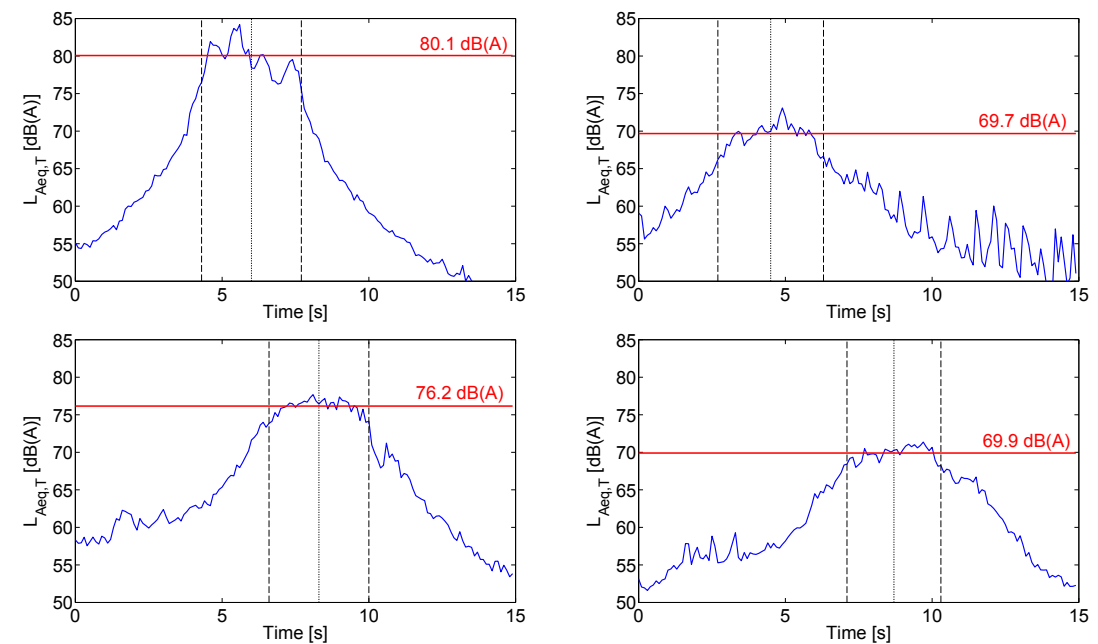

Figure 10: Examples of time histories of $L_{\mathrm{Aeq}, \mathrm{T}}$ in $\mathrm{dB}(\mathrm{A})$ during tram pass-bys, with $\mathrm{T}=100 \mathrm{~ms}$, recorded with the SLM. The dotted line corresponds to the center time, and the two dashed lines correspond to the initial and final instants of the tram pass-by. The pass-by level $L_{\text {Aeq,pass }}$ is the mean level during the pass-by period and is indicated on the plot. Top left: close tram, without barrier. Top right: close tram, with barrier. Bottom left: far tram, without barrier. Bottom right: far tram, with barrier.

pass-by, but one has to determine the time period of integration. Since the speed $v$ of the tram is known for each pass-by, we set the period over which the equivalent level is calculated as the duration of the whole tram pass-by in front of the SLM, given by $\tau=d_{2} / v$ and $d_{2}=43 \mathrm{~m}$ is approximately the total length of the tram (see in Fig. 9). The result is referred to as the pass-by A-weighted equivalent level, written as $L_{\text {Aeq,pass, }}$, and calculated by logarithmic summation of the $L_{\text {Aeq,T }}$ in the corresponding time interval (see examples of this calculation in Fig. 10).

The pass-by levels can then be plotted as a function of speed, for all configurations (see in Fig. 11). The range of tram speeds does vary depending on the configuration, with far trams typically rolling faster (from 40 to $65 \mathrm{~km} / \mathrm{h}$ ) than close trams (from 35 to $55 \mathrm{~km} / \mathrm{h}$ ). There also seems to be a little bias when the barrier was set up, since close trams rolled on average at $46.7 \mathrm{~km} / \mathrm{h}$ without the noise barrier, but at $42.9 \mathrm{~km} / \mathrm{h}$ with the barrier. Proper evaluation of the barrier performance therefore requires to correct for this effect.

Although there seems to be significant variability between the trams pass-bys, there is a positive correlation between levels and speeds in all cases. One can for instance assume a simple power-law dependence of the received power on speed, which in terms of the pass-by level in $\mathrm{dB}$ can be written as $L_{\text {Aeq,pass }}=L_{\text {Aeq,pass,ref }}+\alpha \log \left(v / v_{\text {ref }}\right)$ with $v_{\text {ref }}=40 \mathrm{~km} / \mathrm{h}$ is the reference speed and $L_{\text {Aeq,pass,ref }}$ the reference level. The regression coefficients $L_{\text {Aeq,pass,ref }}$ and $\alpha$ and their uncertainties have been calculated as explained in Appendix A and are tabulated in Table 1 for all configurations. One can notice the coefficients $\alpha$ vary a lot and have a large uncertainty, which suggests pass-by levels do not depend only on speed. Indeed defects in the tram can cause a great variability in levels between the different bogies, as seen for instance in Fig. 8 bottom plots. Besides, propagation effects (due to the ground and the barrier) may affect the coefficients as well. 

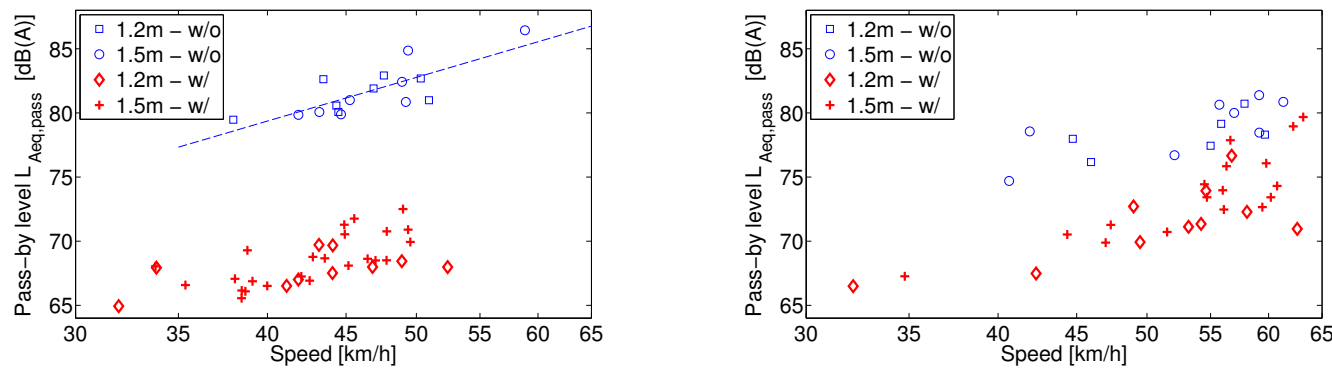

Figure 11: Tram pass-by A-weighted equivalent levels $L_{\text {Aeq.pass }}$ as a function of speed for all measurement configurations The dotted line corresponds to the function $L_{\text {Aeq,pass,ref }}+\alpha \log \left(v / v_{\text {ref }}\right)$ with $L_{\text {Aeq,pass,ref }}=79.3 \mathrm{~dB}(\mathrm{~A}), \alpha=35$ and $v_{\text {ref }}=40 \mathrm{~km} / \mathrm{h}$, which is a regression on the levels for close trams without the barrier. Left - close trams; right - far trams. Symbols: squares - SLM height of $1.2 \mathrm{~m}$, without barrier; circles - SLM height of $1.5 \mathrm{~m}$, without barrier; diamonds: SLM height of $1.5 \mathrm{~m}$, with barrier; crosses: SLM height of $1.5 \mathrm{~m}$, with barrier.

Table 1: Coefficients $L_{\text {Aeq.pass,ref }}$ and $\alpha$ and their uncertainty based on the regression of A-weighted pass-by levels with speed, assuming a dependence of the form $L_{\text {Aeq,pass }}=L_{\text {Aeq,pass,ref }}+\alpha \log \left(v / v_{\text {ref }}\right)$ with $v_{\text {ref }}=40 \mathrm{~km} / \mathrm{h}$, in all configurations Broadband insertion losses in $\mathrm{dB}(\mathrm{A})$ (differences of reference pass-by levels at $v_{\text {ref }}$ ) are also shown.

\begin{tabular}{|c|c|c|c|c|}
\hline \multicolumn{2}{|c|}{ Configuration } & $\begin{array}{l}L_{\text {Aeq,pass,ref }} \\
{[\mathrm{dB}(\mathrm{A})]}\end{array}$ & $\begin{array}{l}\text { Speed-dependence } \\
\text { coefficient } \alpha\end{array}$ & $\begin{array}{c}\text { Barrier insertion loss } \\
\text { estimate at } 40 \mathrm{~km} / \mathrm{h}[\mathrm{dB}(\mathrm{A})]\end{array}$ \\
\hline Close $-1.2 \mathrm{~m}$ & $\begin{array}{l}\text { without barrier } \\
\text { with barrier }\end{array}$ & $\begin{array}{l}80.3 \pm 0.6 \\
67.5 \pm 0.4\end{array}$ & $\begin{array}{c}19 \pm 10 \\
12 \pm 6\end{array}$ & $12.8 \pm 1$ \\
\hline Close $-1.5 \mathrm{~m}$ & $\begin{array}{l}\text { without barrier } \\
\text { with barrier }\end{array}$ & $\begin{array}{l}78.4 \pm 0.7 \\
67.7 \pm 0.3\end{array}$ & $\begin{array}{l}48 \pm 10 \\
29 \pm 6\end{array}$ & $10.6 \pm 0.8$ \\
\hline Far $-1.2 \mathrm{~m}$ & $\begin{array}{l}\text { without barrier } \\
\text { with barrier }\end{array}$ & $\begin{array}{l}76.1 \pm 1.2 \\
68.7 \pm 1.0\end{array}$ & $\begin{array}{l}18 \pm 11 \\
26 \pm 9\end{array}$ & $7.5 \pm 1.5$ \\
\hline Far $-1.5 \mathrm{~m}$ & $\begin{array}{l}\text { without barrier } \\
\text { with barrier }\end{array}$ & $\begin{array}{l}75.9 \pm 1.1 \\
68.4 \pm 1.0\end{array}$ & $\begin{array}{l}25 \pm 9 \\
40 \pm 7\end{array}$ & $7.5 \pm 1.5$ \\
\hline
\end{tabular}

However, we will assume that tramway noise source power levels depend only on speed, as done in [26]. In order to evaluate the dependence of the power levels, one needs to avoid as much influence of propagation effects as possible. Besides, the configuration in which propagation will have the smallest effect is for the close tram without the noise barrier. We will therefore assume that the dependence of the source power levels can be approximated by the dependence of the pass-by levels for close trams (for both receiver positions). This yields a coefficient of $\alpha=35 \pm 8$, which is in good agreement with the value of 32.7 measured by Pallas et al. for a modern tram in the case of soft pads and pavings [26], although the uncertainty is in our case still important. From now on, we will define the speed-corrected value of any level $L$ at $v_{\text {ref }}=40 \mathrm{~km} / \mathrm{h}$ as $L^{\prime}=L-35 \log \left(v / v_{\text {ref }}\right)$. Finally, one can evaluate the speed-independent effect of the barrier in each configuration by comparing the $L_{\text {Aeq,pass, ref }}$ with and without the barrier (see the last column of Table 1), which is a reduction on average of more than $10 \mathrm{~dB}(\mathrm{~A})$ for close trams, and 7.5 $\mathrm{dB}(\mathrm{A})$ for far trams. One can already state that the effect of the barrier prototype, although its length is only half of that of the tram, is significant.

\subsection{Analysis of the $L_{\text {Aeq,T }}$ time histories}

Another way of measuring the effect of the barrier is to analyze the measured $L_{\mathrm{Aeq}, \mathrm{T}}$ time histories (again here $\mathrm{T}=100 \mathrm{~ms}$ ). This will allow one to have a closer look at the noise reduction effect considering a time dependence. However, since the measurements were not synchronized, 
one first has to process the histories in order for them to have a similar center time (instant at which the center of the tram is the closest to the SLM). Besides, one needs to correct for the effect of speed, both on time and level. This will then allow one to make an elementary statistical analysis of the time histories, by considering the mean and the dispersion of the levels as a function of time.

The center time $t_{c}$ of each time history is evaluated as the center time of the tram pass-by as defined in section 4.1. The centered time $\tau$ is then defined for each pass-by as $\tau=t-t_{c}$. The $L_{\mathrm{Aeq}, \mathrm{T}}$ levels and centered time $\tau$ are then corrected due to the speed dependence as:

$$
L_{\text {Aeq, } \mathrm{T}}^{\prime}=L_{\text {Aeq,T }}-35 \log \left(\frac{v}{v_{\text {ref }}}\right) \quad \tau^{\prime}=\frac{v}{v_{\text {ref }}} \tau
$$

Since the corrected histories are no longer defined on the same instants, a linear interpolation in time is made. An example of this process is shown in Fig. 12.
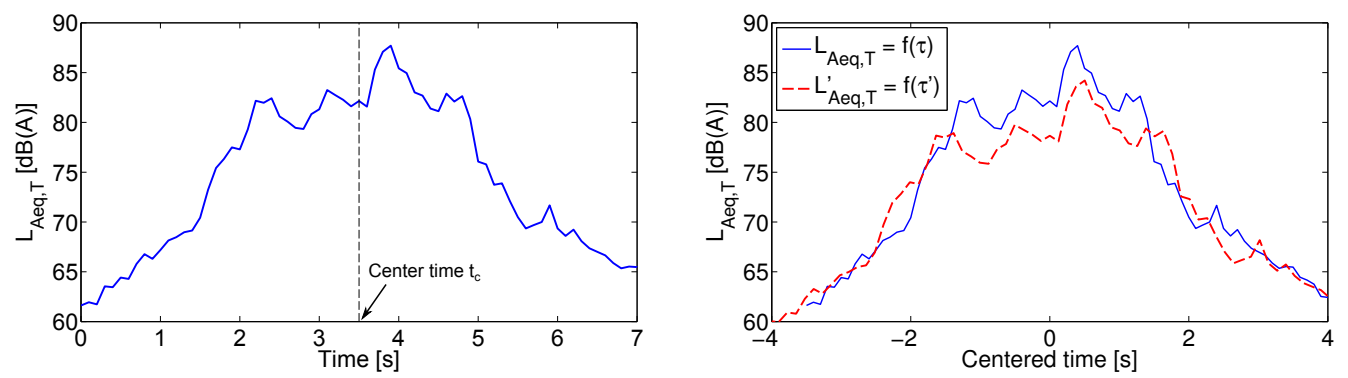

Figure 12: Example of a $L_{\mathrm{Aeq}, \mathrm{T}}$ time history (close tram - $1.20 \mathrm{~m}$ - without barrier) and application of the speed correction on time and level. Left: measured time history and center time $t_{c}$. Right: measured time history of the $L_{\mathrm{Aeq}, \mathrm{T}}$ as a function of centered time $\tau=t-t_{c}$ (solid line) and corrected time history of the $L_{\mathrm{Aeq}, \mathrm{T}}^{\prime}$ as a function of corrected centered time $\tau^{\prime}$ (dashed line).

Mean and dispersion calculations are then made at each instant on the corrected histories, based on the different pass-bys for all measurement configurations. Results are shown in Fig. 13. One can also notice that there is a strong variability of the levels, even after the speed correction is applied, which is certainly related to the different trams having different defects as pointed out earlier. Nevertheless, the main result from this approach is that, at the considered receiver locations, the noise reduction effect of the barrier is effective during the whole pass-by (attenuation of 4-7 $\mathrm{dB}(\mathrm{A})$ for far trams, and of 9-15 $\mathrm{dB}(\mathrm{A})$ for close trams), despite the small length of the barrier compared to that of the tram. Indeed, when $\tau$ is large in absolute value, a smaller portion of the tram - which as a first approximation can be approximated as the region where most of the noise is generated - is "hidden" by the noise barrier (see in Fig. 14), and therefore one might have observed a negligible noise reduction effect. This aspect also strongly depends on the directivity of the sources in the horizontal plane, which is difficult to evaluate directly with simple SLM measurements. However, based on the fact that the barrier does have an effect even at large values of $\tau$, it seems like the main noise sources of this type of tram namely wheel radiation and rolling noise - have rather narrow horizontal directivity patterns.

One can also point out that the issue of noise reduction limitation due to the finite size of a noise barrier will be more important if the receiver was further away from the track, but in this case even without any noise barrier the received level would be smaller and therefore the pass-by of a tram might not cause as much of a nuisance. 

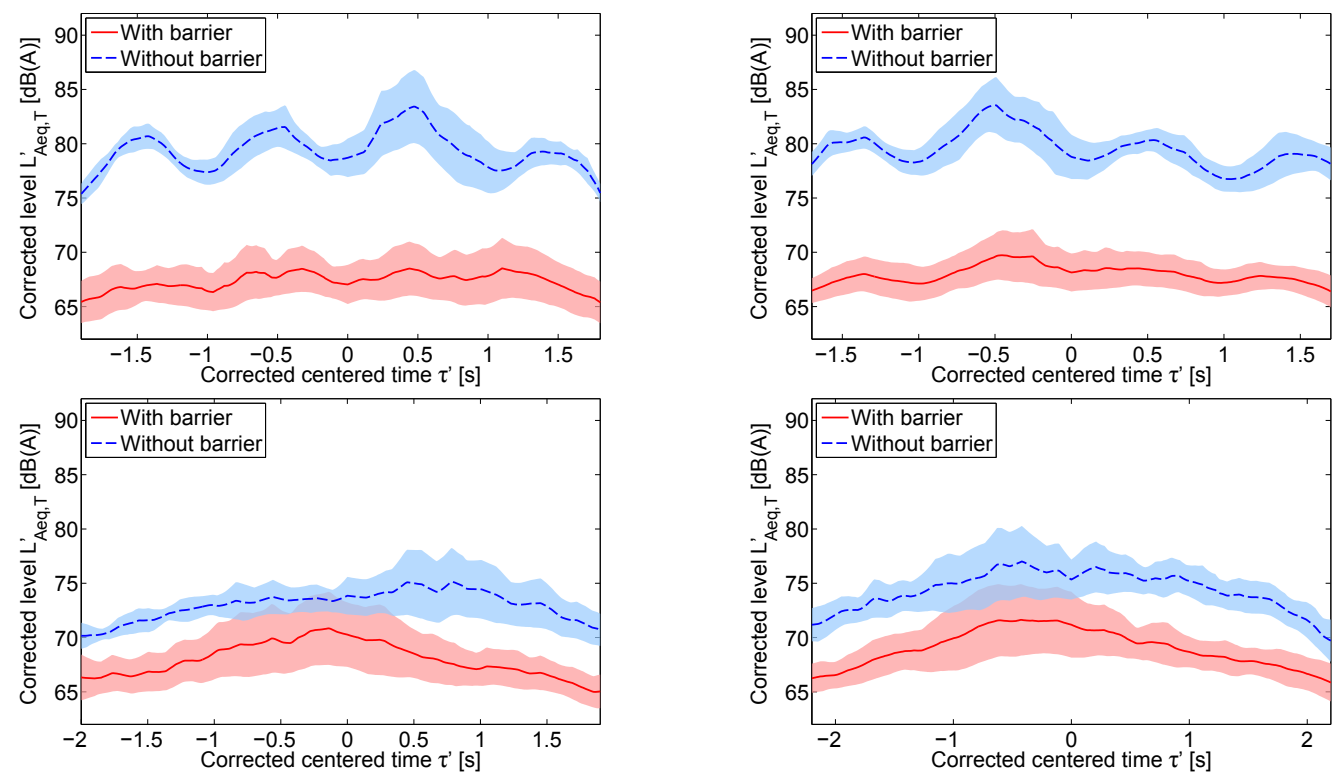

Figure 13: Mean and dispersion interval (plus and minus one standard deviation from the mean) of corrected levels $L_{\text {Aeq,T }}^{\prime}$ time histories in $\mathrm{dB}(\mathrm{A})$ during tram pass-bys as a function of corrected centered time $\tau^{\prime}$, with (solid line) and without (dashed line) the noise barrier. Top left: close tram, height of $1.20 \mathrm{~m}$. Top right: close tram, height of $1.50 \mathrm{~m}$. Bottom left: far tram, height of $1.20 \mathrm{~m}$. Bottom right: far tram, height of $1.50 \mathrm{~m}$.

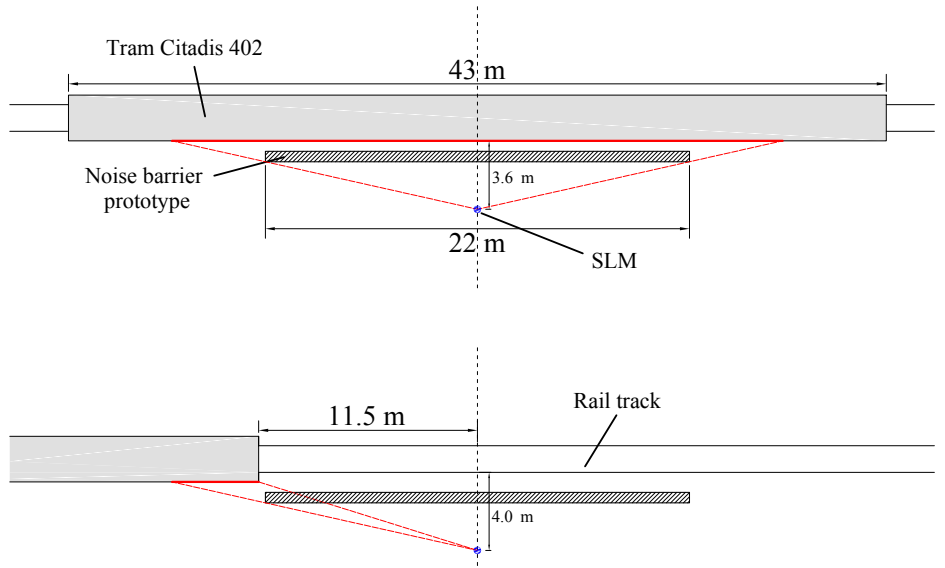

Figure 14: Schematic top view of the noise barrier prototype in case of the pass-by of a close tram. The solid thick lines delimit the approximate part of the noise source region which the barrier can attenuate, based on purely geometrical considerations. The top plot corresponds to a value of $\tau=0 \mathrm{~s}$, for which most of the source region is geometrically hidden by the barrier. The bottom plot corresponds to value of $\tau=-2 \mathrm{~s}$ (the tram is assumed to roll at $40 \mathrm{~km} / \mathrm{h}$ ), in which only a small portion of the region is geometrically hidden. 


\subsection{Spectral analysis and third-octave insertion losses}

Instead of comparing broadband levels such as the $L_{\mathrm{Aeq}, \mathrm{T}}$ or the $L_{\mathrm{Aeq} \text {,pass }}$, one may wish to evaluate the insertion loss of the noise barrier for different third-octave bands, which would allow one to compare the measurement with BEM calculations. This can be achieved by performing simple spectral analysis of the recorded signals.

However, as stated above, the presence of background noise in the surrounding environment can bias the evaluation of the low-height barrier insertion loss. Although the site was relatively quiet, which means that broadband levels such as the $L_{\text {Aeq,T }}$ were sufficient above the background levels, this might not be true any more depending on which third-octave band is considered. We will therefore first analyze the data to find the frequency range in which the SNR was sufficiently good to evaluate the insertion loss accurately.

\subsubsection{Effect of noise on insertion loss evaluation and considered frequency range}

First of all, one can theoretically evaluate what is the influence of background noise on the evaluation of the insertion loss. Let $P_{\mathrm{w}}$ and $P_{\text {wo }}$ typical pressure spectrum values at a given receiver location and in a given frequency band - they can be for instance the square root of the integrated value of the power spectral density (PSD) over a third-octave band -, with and without the noise barrier, in an ideal environment without any background noise. The ideal attenuation provided by the barrier is then $A=P_{\mathrm{w}}^{2} / P_{\text {wo }}^{2}$ and the insertion $\operatorname{loss} \mathrm{IL}=-10 \log A$. However, in reality, what is measured is an approximate attenuation given by $\tilde{A}=\left(P_{\mathrm{w}}^{2}+N_{\mathrm{w}}^{2}\right) /\left(P_{\mathrm{wo}}^{2}+N_{\mathrm{wo}}^{2}\right)$, with $N_{\mathrm{w}}$ and $N_{\text {wo }}$ typical spectra of uncorrelated background noises, which may be different between the measurement made with the barrier compared to that made without. Now define the quantity $s_{\mathrm{W}}=P_{\mathrm{w}}^{2} / N_{\mathrm{w}}^{2}$ and $s_{\mathrm{wo}}=P_{\mathrm{wo}}^{2} / N_{\mathrm{wo}}^{2}$. These quantities are related to the signal-to-noise ratios $\mathrm{SNR}_{\mathrm{w}}$ and $\mathrm{SNR}_{\mathrm{wo}}$ by $\mathrm{SNR}_{\mathrm{w}}=10 \log s_{\mathrm{w}}$ and $\mathrm{SNR}_{\mathrm{wo}}=10 \log s_{\mathrm{wo}}$. Then the ratio of the measured attenuation to the ideal attenuation is:

$$
\frac{\tilde{A}}{A}=\frac{1+1 / s_{\mathrm{w}}}{1+1 / s_{\mathrm{wo}}}
$$

Due to the sound attenuation provided by the noise barrier, one typically has $P_{\mathrm{w}}<P_{\mathrm{wo}}$. Besides, if one assumes the background noise levels to be similar, that is $N_{\mathrm{w}} \approx N_{\mathrm{wo}}$, one has $s_{\mathrm{w}}<s_{\mathrm{wo}}$ (which also means $\mathrm{SNR}_{\mathrm{w}}<\mathrm{SNR}_{\mathrm{wo}}$ ) and therefore from Eq. (1), one has $\tilde{A}>A$, that is $\widetilde{\mathrm{IL}}<$ IL, where $\widetilde{\mathrm{IL}}$ is the estimated insertion loss in the presence of noise. This means that in most situations, the insertion loss measured in the presence of noise will be under-evaluated.

Now, say that we can ensure the two SNRs are above a certain value $\mathrm{SNR}_{\min }$. It is equivalent to state that $s_{\mathrm{w}, \text { wo }}>s_{\min }$ with $s_{\min }=10^{\left(\mathrm{SNR}_{\min } / 10\right)}$. Using this relationship in Eq. (1), we have:

$$
\frac{\tilde{A}}{A}<1+1 / s_{\text {smin }}
$$

Defining the error on the measured insertion loss as $\Delta \mathrm{IL}=\mathrm{IL}-\widetilde{\mathrm{IL}}>0$, this last equation can be rewritten as $\Delta \mathrm{IL}<\Delta \mathrm{IL}_{\max }$ with:

$$
\Delta \mathrm{IL}_{\max }=10 \log \left(1+1 / s_{\min }\right)=10 \log \left(1+10^{-\left(\mathrm{SNR}_{\min } / 10\right)}\right)
$$

$\Delta \mathrm{IL}_{\max }$ is an indicator of the error on the insertion loss measured value, which is related to the minimum SNR. This relationship can therefore be used to find an appropriate value of $\mathrm{SNR}_{\min }$ 
in order to have a limited error on the insertion loss. Say we would like the error on the insertion loss to be less than $\Delta \mathrm{IL}_{\max }=0.5 \mathrm{~dB}$, the corresponding minimum SNR will be:

$$
\mathrm{SNR}_{\min }=-10 \log \left(10^{\left(\Delta \mathrm{IL}_{\max } / 10\right)}-1\right)=9 \mathrm{~dB}
$$

One can therefore use this criterion to select the frequency bands in which the barrier insertion loss will be evaluated correctly (within $0.5 \mathrm{~dB}$ ), without too much influence of the background noise. The SNR over each third-octave has been evaluated by considering the signal portion of each recording as the tram pass-by (as defined in section 4.1) and the noise portion as the initial or last two seconds of the recording (depending on the pass-by center time). The third-octave levels of the signal are calculated by integration of the PSD of the signal portion over the corresponding band. Similar calculations are performed to evaluate the third-octave levels of the background noise. An example is shown in Fig. 15. Applying this process for all the recordings, it has been found that for $90 \%$ of them the SNR was above $9 \mathrm{~dB}$ in the frequency range $[200 \mathrm{~Hz}-2500$ $\mathrm{Hz}]$, which will be the range of study in the rest of this section. Indeed, it has been noticed that tramway noise emissions at low frequencies are usually comparable to typical background noise, and that at higher frequencies, birds singing significantly increase the background noise between 3 and $4 \mathrm{kHz}$.

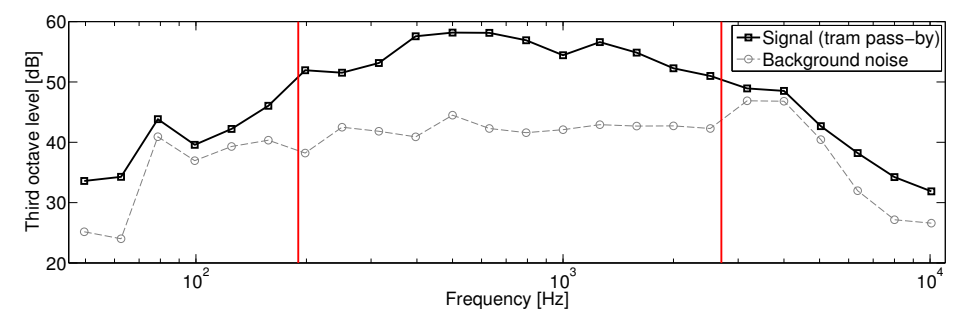

Figure 15: Examples of signal and background noise third-octave levels in dB ref. $20 \mu \mathrm{Pa}$ (far tram - SLM height of $1.20 \mathrm{~m}$ - with barrier). The vertical lines delimit the frequency range in which the SNR is sufficiently high (above $9 \mathrm{~dB}$ ). The bump in the background noise spectrum at 3 and $4 \mathrm{kHz}$ correspond to birds singing. Thick solid line: signal - dashed thin line: background noise.

\subsubsection{Measured third-octave insertion losses}

Now that the trusted frequency band has been determined, one can calculate for a given configuration the insertion loss of the low-height barrier from third octave levels without the barrier, averaged over all measurements, minus averaged third octave levels with the barrier. Apart from the uncertainty due to the background noise, there is some variability in this evaluation which can be quantified by classical uncertainty calculations. Results are presented in Fig. 16. First of all, it is clear that the low-height barrier provides attenuation over the whole considered frequency range, both for close and far trams, although the attenuation is a lot higher for close trams. One can also notice that at the receiver height of $1.20 \mathrm{~m}$, the performance of the noise barrier for far trams is increased at high frequencies compared to that measured at $1.50 \mathrm{~m}$, which is consistent with the fact that one receiver is deeper into the shadow zone than the other. This difference between the two receiver heights is however smaller for close trams, since both receivers are well into the shadow zone in this case.

One can then consider a broadband insertion loss in $\mathrm{dB}(\mathrm{A})$ in the considered frequency range - 200 to $2500 \mathrm{~Hz}$. Levels are first converted to $\mathrm{dB}(\mathrm{A})$ by applying the A-weighting correction to 

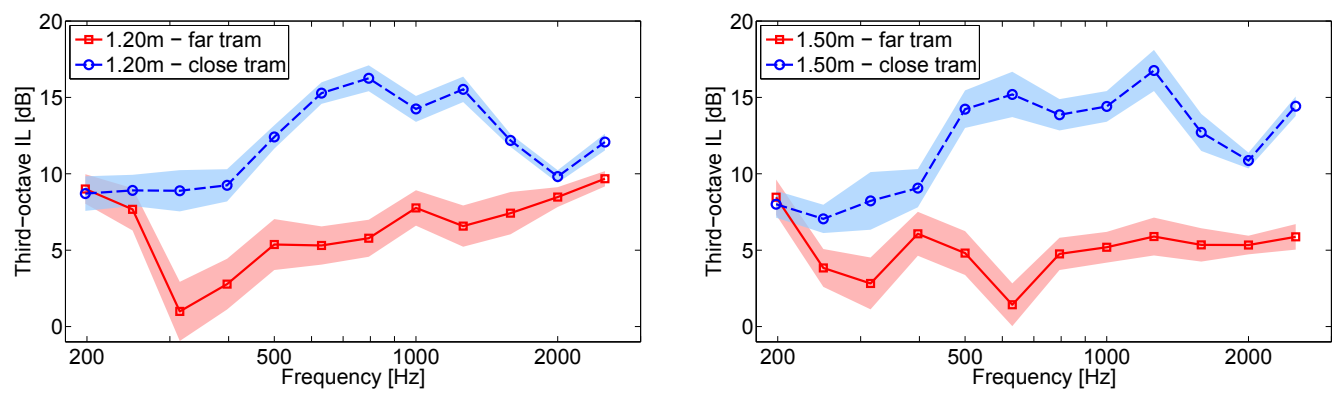

Figure 16: Mean values and uncertainty interval of measured third-octave insertion losses in $\mathrm{dB}$ in the different configurations in the frequency range $200-2500 \mathrm{~Hz}$. Left: SLM height of $1.20 \mathrm{~m}$ - right: SLM height of $1.50 \mathrm{~m}$. Solid line: far tram - dashed line: close tram.

Table 2: Mean value and uncertainty of broadband insertion losses in the $200-2500 \mathrm{~Hz}$ range based on A-weighted third-octave levels with and without the barrier, for all configurations.

\begin{tabular}{c|c} 
Configuration & $\begin{array}{c}\mathrm{IL}_{200-2500}[\mathrm{~dB}(\mathrm{~A})] \\
(200-2500 \mathrm{~Hz} \text { range })\end{array}$ \\
\hline Close tram $-1.2 \mathrm{~m}$ & $13.3 \pm 0.6$ \\
Close tram $-1.5 \mathrm{~m}$ & $13.8 \pm 1.2$ \\
Far tram - $1.2 \mathrm{~m}$ & $5.5 \pm 1.2$ \\
Far tram - $1.5 \mathrm{~m}$ & $4.3 \pm 1.1$
\end{tabular}

the third octave levels. The broadband insertion loss $\mathrm{IL}_{200-2500}$ is then evaluated as:

$$
\mathrm{IL}_{200-2500}=10 \log \left(\sum_{j} 10^{\left(L_{A, j}^{\mathrm{wo}} / 10\right)}\right)-10 \log \left(\sum_{j} 10^{\left(L_{A, j}^{\mathrm{w}} / 10\right)}\right)
$$

in which $L_{A, j}^{\mathrm{wo}}$ (resp. $L_{A, j}^{\mathrm{w}}$ ) are the A-weighted third-octave levels in the band of index $j$ without the barrier (resp. with the barrier). Corresponding uncertainties are evaluated as well. Results are shown in Table 2. As already mentioned, the difference between the two receiver heights is significant for far trams, but not for close trams. It is however surprising that, in the close tram case, the mean insertion loss is smaller at $1.2 \mathrm{~m}$ than at $1.5 \mathrm{~m}$. Let us recall that there is significant uncertainty in the evaluation of the measured broadband performance and therefore these results should be considered accordingly.

Besides, these results are a little different than the first estimate of the broadband insertion loss shown in section 4.1, which might be due to the fact that no speed correction was applied on the third-octave levels, and also since the evaluation based directly on the measured passby levels was evaluated on a larger frequency band, but was also more subject to error due to the background noise implicitly present in the levels estimation. The choice not to apply a speed correction on the third-octave levels was based on the fact that such a correction should be dependent on the considered third-octave band (as done in [26]), but in our case it has been found that the uncertainty on the regression coefficients was very high for most frequency bands and therefore the coefficients not meaningful.

\section{Comparison with simple BEM calculations}

The third-octave insertion losses calculated in the previous section can now be compared to 2D BEM calculations. It is expected that the results of the BEM predictions will be different 
from the measurements since the situation modeled in the numerical simulations will be a lot simpler than the real environment: infinitely extended geometry, omnidirectional coherent line source, position of the sources, approximate geometry, approximate acoustic properties of the surrounding surfaces (ground, tram and low-height barrier). It would however be interesting to have an estimate of this difference.

Due to the lack of more accurate data, the ground and the tram are assumed perfectly rigid in the numerical model, as well as the pressed wood boards in which the barrier is made. The fiberglass is assumed to be a fibrous layer modeled with the Delany and Bazley model [28], with a flow resistivity of $\sigma=30 \mathrm{kPa} . \mathrm{s} / \mathrm{m}^{2}$ and a thickness of $d=8 \mathrm{~cm}$. Two sources located at each rail are considered, and their contributions are summed incoherently. Two receivers respectively located at heights of $1.20 \mathrm{~m}$ and $1.50 \mathrm{~m}$ are considered, similarly to what has been done in the measurements. The geometries used in the simulations are presented in Fig. 17. The spectral content of the sources is not important to estimate the third-octave insertion losses, but will be added when evaluating the broadband insertion loss.
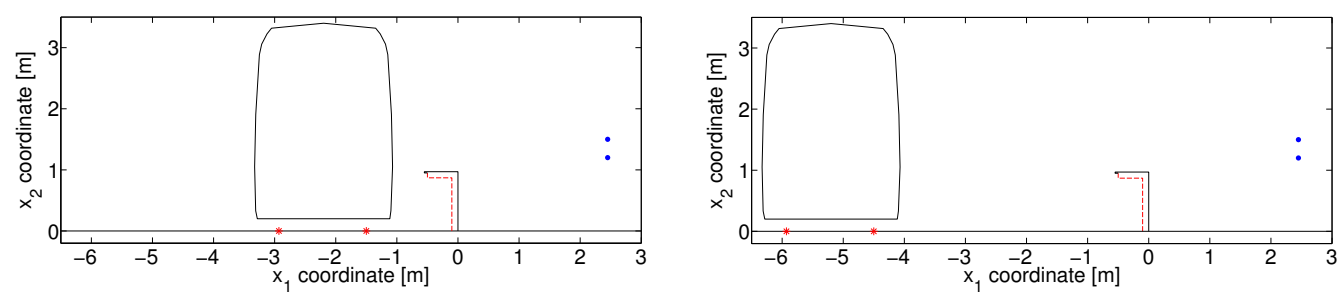

Figure 17: Considered geometries for 2D BEM calculations. Symbols: dots - receiver locations; stars: sources. Boundary coding: solid line - rigid; dashed line - fibrous layer (Delany and Bazley model with parameters $\sigma=30 \mathrm{kPa} . \mathrm{s} / \mathrm{m}^{2}$ and $d=8 \mathrm{~cm})$. Left: close tram; right: far tram.
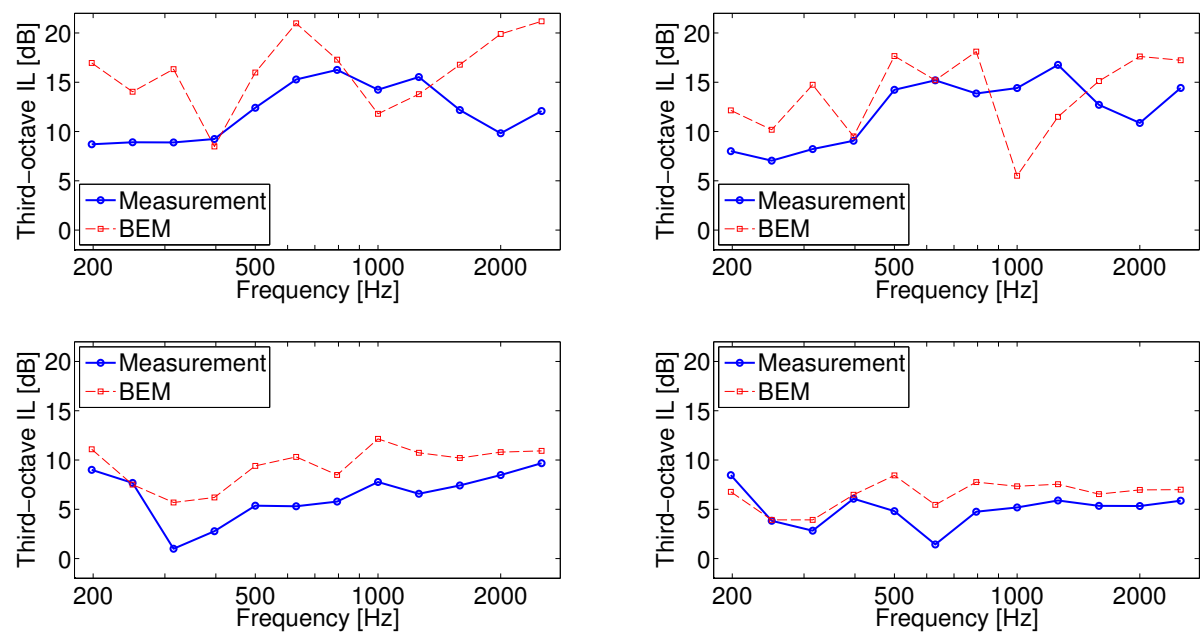

Figure 18: Comparison of mean measured values and BEM calculated values of third octave insertion losses. BEM calculations are done using the geometry given in Fig. 17. Thick solid line: measurement; thin dashed line: BEM calculation. Top left: close tram - SLM at $1.2 \mathrm{~m}$; top right: close tram - SLM at $1.5 \mathrm{~m}$; bottom left: far tram - SLM at $1.2 \mathrm{~m}$; bottom right: far tram - SLM at $1.5 \mathrm{~m}$. 
Table 3: Measured and calculated broadband insertion losses in the $200-2500 \mathrm{~Hz}$ range, for all configurations. The calculation is done using Eq. (3).

\begin{tabular}{c||c|c}
\multirow{2}{*}{ Configuration } & \multicolumn{2}{c}{$\mathrm{IL}_{200-2500}^{*}[\mathrm{~dB}(\mathrm{~A})]$} \\
\cline { 2 - 3 } & Measurement & BEM calculation \\
\hline Close tram - $1.2 \mathrm{~m}$ & 13.6 & 14.8 \\
Close tram - $1.5 \mathrm{~m}$ & 13.7 & 11.3 \\
Far tram - $1.2 \mathrm{~m}$ & 6.1 & 9.7 \\
Far tram - $1.5 \mathrm{~m}$ & 4.5 & 6.8
\end{tabular}

Comparison between BEM and measured third octave insertion losses are presented in Fig. 18. Although significant differences exist, one can notice the general trends are relatively wellrepresented in the BEM calculation. Nevertheless, in the close tram case, the performance is largely overestimated at low and high frequencies. There is also a uniform overestimation of the BEM in the far tram case, which may be due to a ground effect happening in reality which is not taken into account in the calculation (since the ground has not been characterized properly on site), or to the finite extent of the barrier. Besides, some peaks and dips in the insertion loss curve, probably related to interference effects, are typically more marked in the BEM calculation compared to the measurements, which is probably related to the simple modeling of the noise sources (coherent line source).

Furthermore, one can evaluate a broadband insertion based on the BEM predicted insertion losses, using a measured spectrum. Let $L_{A, j}^{\text {in }}$ the mean A-weighted levels measured without the barrier for a given configuration, taken as an estimate of the power spectrum of the source. One can then evaluate the broadband insertion loss in the $200-2500 \mathrm{~Hz}$ range based on this spectrum and third-octave insertion losses $\mathrm{IL}_{j}$ as:

$$
\mathrm{IL}_{200-2500}^{*}=10 \log \left(\sum_{j} 10^{\left(L_{A, j}^{\mathrm{in}} / 10\right)}\right)-10 \log \left(\sum_{j} 10^{\left(L_{A, j}^{\mathrm{in}} / 10\right)} 10^{\left(-\mathrm{IL}_{j} / 10\right)}\right)
$$

which is a similar definition than that given in Eq. (2). The values $\mathrm{IL}_{j}$ can be taken as measured values or calculated values. For the BEM predictions, calculations are made with 20 frequencies per third-octave using the geometry shown in Fig. 17, with and without the low-height barrier. Besides, in each case the two source contributions are summed incoherently. Results are summarized in Table 3. Measured values are slightly different from those given in Table 2 since in Table 3 the evaluation is based on an average source spectrum and average attenuations, whereas in Table 2 the evaluation was based on the difference between broadband average levels. This distinction was necessary since BEM calculations cannot predict broadband levels directly (due to the 2D approximation), which implies that in order to compare measured and predicted performances, one therefore has to use third-octave insertion losses and one source spectrum, as done in Eq. (3).

One can notice in the far tram case a difference of about 3-4 $\mathrm{dB}(\mathrm{A})$ between the measured and calculated broadband insertion loss for both receiver heights. This difference is smaller in the close tram case (1-2 dB(A)). Furthermore, although the BEM predicts a significant difference in the close tram case between the two receiver positions, which is consistent with the fact that one of them is deeper in the shadow zone, this is not observed in the measurement as pointed out in the previous section.

The main result of this comparison between attenuations obtained from simple 2D BEM calculations and from in situ measurements is that, even though many features of the problem are not reproduced in the model, calculations yield results which are at least in the ballpark of 
in situ measurements - that is within a few $\mathrm{dB}(\mathrm{A})$-, especially for the close tram case which is the one we are mostly interested in. This suggests that BEM numerical predictions are likely to represent the in situ performance - that is the broadband insertion loss - of such low height noise barriers, with an accuracy of a few $\mathrm{dB}(\mathrm{A})$.

\section{Conclusion}

A full scale prototype of a tram low height noise barrier has been built and implemented in a real environment, along the B line of the Grenoble tramway system, in the town of Saint-Martind'Hères. A simple L-shape design made of pressed wood and fiberglass, for a length of $22 \mathrm{~m}$, is proposed. The design of the noise barrier as well as its length were chosen essentially to cope with feasibility and time constraints. A series of pass-by measurements were performed at a close location from the tram track, at two different heights, with and without the noise barrier. The tram speed has been measured as well using an auxiliary microphone located very close to the track.

First, a positive correlation has been found between pass-by equivalent level and speed, in agreement with previous studies. This was used to approximately correct for the speed in passby equivalent levels and time histories. Although a significant variability is found between the different trams, it is shown that the barrier provides on average an attenuation of more than 10 $\mathrm{dB}(\mathrm{A})$ for close trams, and of more than $5 \mathrm{~dB}(\mathrm{~A})$ for far trams, during the whole pass-by, and not only when the barrier covers most of the tram length.

The effect of the noise barrier in the frequency domain has been studied as well. It is found that the barrier provides attenuation in the whole frequency range $200-2500 \mathrm{~Hz}$ (which is the range in which the effect of the barrier could be evaluated accurately), which yields a broadband insertion loss in this range of $13 \mathrm{~dB}(\mathrm{~A})$ for close trams, and $5 \mathrm{~dB}(\mathrm{~A})$ for far trams. Simplistic BEM calculations are made as well, and it is found that although the environment is highly idealized in the calculations, predictions yield rather good estimates of the actual in situ performance, within a few $\mathrm{dB}(\mathrm{A})$, especially for the close tram case.

Finally, based on the experimental data collected during this work, one can state that low height noise barriers can be efficient solutions to attenuate tramway noise for close receivers, namely pedestrians and cyclists. It is also likely that this type of noise protection could be efficient as well against any urban noise source located close to the ground, as long as it can be placed close to the source. More efficient - using more complicated shapes or more efficient sound absorbing materials - and more sustainable - for instance using vegetation or natural materials - designs could certainly be achieved as well, which will truly make low-height barriers both efficient and sustainable solutions to decrease the issue of noise exposure outdoors in urban areas.

\section{Acknowledgments}

The authors would like to acknowledge the many people who were involved in this work, particularly Jean-François Buisson who has been a key person in the success of this experiment as the builder of the prototype and supervisor of the on-site installation. Extra thanks go to Frank Vivien, Grégory Ruinat, Julien Maillard et Pascal Ducruet for their valuable additional help. The authors also acknowledges the town of Saint-Martin-d'Hères and the company SEMITAG for their collaboration. Finally, the authors would like to thank the French Ministry of Ecology, Sustainable Development and Energy (MEDDE) for the financial support of this work. 
[1] D. Ouis, Annoyance from road traffic noise: a review, J. Environ. Psychol. 21 (2001) 101-120.

[2] Burden of disease from environmental noise, Technical Report, World Health Organization (Regional office for Europe) and the Joint Research Centre (European Commission), 2011.

[3] Guidelines for community noise, Technical Report, World Health Organization (Regional office for Europe), 1999

[4] K. Horoshenkov, D. C. Hothersall, S. E. Mercy, Scale modelling of sound propagation in a city street canyon, J. Sound Vib. 223 (1999) 795-819.

[5] M. Baulac, Optimisation des protections anti-bruit routières de forme complexe (optimization of complex traffic noise barriers), Ph.D. thesis, Université du Maine (Le Mans, France), 2006.

[6] M. Baulac, J. Defrance, P. Jean, F. Minard, Efficiency of noise protections in urban areas: prediction and scale model measurements, Acta Acust. united Ac. 92 (2006) 530-539.

[7] M. Baulac, J. Defrance, P. Jean, Optimization of low height noise protections in urban areas, in: Forum Acousticum 2005, Budapest, Hungary, pp. 1075-1080.

[8] P. J. Thorsson, Optimisation of low-height noise barriers using the equivalent sources method, Acta Acust. 86 (2000) 811-820

[9] P. J. Thorsson, Combined effects of admittance optimisation on both barrier and ground, Appl. Acoust. 64 (2003) $693-711$.

[10] F. Koussa, Evaluation de la performance acoustique des protections antibruit innovantes utilisant des moyens naturels : application aux transports terrestres (Evaluation of the acoustic efficiency of innovative noise barriers using natural means: application to ground transportation systems), Ph.D. thesis, Ecole Centrale de Lyon (Lyon, France), 2012.

[11] F. Koussa, J. Defrance, P. Jean, P. Blanc-Benon, Acoustic performance of gabions noise barriers: numerical and experimental approaches, Appl. Acoust. (2013) 189-197.

[12] M. Rådsten-Ekman, B. Vincent, C. Anselme, A. Mandon, R. Rohr, J. Defrance, D. van Maercke, D. Botteldooren, M. E. Nilsson, Case-study evaluation of a low and vegetated noise barrier in an urban public space, in: Proc. Internoise 2011, Osaka, Japan.

[13] L. Ding, T. Van Renterghem, D. Botteldooren, Estimating the effect of semi-transparent low-height road traffic noise barriers with ultra weak formulation, Acta Acust. united Ac. 97 (2011) 391-402.

[14] J. Defrance, P. Jean, F. Koussa, K. Horoshenkov, A. Khan, H. Benkreira, T. Van Renterghem, J. Kang, J. Smyrnowa, J. Forssén, Innovative barriers exploiting natural materials: application to innovations, Deliverable 2.3, Collaborative Project HOSANNA (FP7/2007-2013 grant agreement n 234306), 2013.

[15] J. Defrance, P. Jean, F. Koussa, K. Horoshenkov, A. Khan, H. Benkreira, T. Van Renterghem, J. Kang, J. Smyrnowa, Innovative barriers exploiting natural materials: analysis and recommendations, Deliverable 2.4, Collaborative Project HOSANNA (FP7/2007-2013 grant agreement n 234306), 2013.

[16] A. Jolibois, A sensitivity-based approach to optimize the surface treatment of a low-height tramway noise barrier Ph.D. thesis, The Pennsylvania State University (University Park, PA, USA), 2013.

[17] A. Jolibois, D. Duhamel, V. W. Sparrow, J. Defrance, P. Jean, Scattering by a cylinder covered with an arbitrary distribution of impedance and application to the optimization of a tramway noise abatement system, J. Sound Vib. 331 (2012) 5597-5622.

[18] A. Jolibois, D. Duhamel, V. W. Sparrow, J. Defrance, P. Jean, Application of admittance optimization to the design of a low-height tramway noise barrier, in: Proc. Internoise 2012, New York City, NY, USA.

[19] P. Fernandez, I. Diez, J. L. Eguiguren, I. Aspuru, Noise barriers customized to abate non conventional noise sources, in: Proc. Internoise 2013, Innsbruck, Austria.

[20] R. Rylander, Björkman, U. Åhrlin, S. Sörensen, Tram noise in city traffic, J. Sound Vib. 51 (1977) 353-358.

[21] Y. K. Wijnia, Noise emission from trams, J. Sound Vib. 120 (1988) 281-286.

[22] H. M. E. Miedama, R. Van den Berg, Community response to tramway noise, J. Sound Vib. 120 (1988) $341-346$.

[23] J. Mandula, B. Salaioá, M. Koval'aková, Prediction of noise from trams, Appl. Acoust. 63 (2002) 373-389.

[24] C. Philipps-Bertin, P. Champelovier, C. Trindade, J. Lambert, Caractérisation des sources et évaluation de la perception du bruit et des vibrations des tramways (Source identification and perception evaluation of tramway noise and vibrations), Technical Report, INRETS-LTE (ADEME grant number 04.03.C0053), 2006.

[25] M.-A. Pallas, J. Lelong, R. Chatagnon, Tram noise emission: spectral analysis of the noise source contribution, in: Proc. Acoustics'08, Paris, France.

[26] M.-A. Pallas, J. Lelong, R. Chatagnon, Characterization of tram noise emission and contribution of the noise sources, Appl. Acoust. 72 (2011) 437-450.

[27] S. Sandrock, B. Griefahn, T. Kaczmarek, H. Hafke, A. Preis, T. Gjestland, Experimental studies of annoyance causes by noises from trams and buses, J. Sound Vib. 313 (2008) 908-919.

[28] M. E. Delany, E. N. Bazley, Acoustical properties of fibrous absorbent materials, Appl. Acoust. 3 (1970) 105-116.

[29] J. W. Kirchner, Data analysis toolkits, provided for the analysis of environmental data class, 2001. 


\section{Appendix A. Uncertainty evaluation of linear regression parameters}

In this section are recalled some results of linear regression analysis used in this paper to estimate linear dependence coefficients as well as their uncertainties. All the results given in this section are essentially taken from a set of lecture notes [29]. A set of $n$ points of coordinates $\left(x_{i}, y_{i}\right)$ is considered and it is assumed that the variable $y$ can be described approximately as a linear function of $x$ of the form: $y=a x+b$. We wish to find the most appropriate values of $a$ and $b$ as well as the corresponding uncertainties.

Let $\bar{x}$ and $\bar{y}$ the mean value of $x$ and $y$, and $\sigma_{x}$ and $\sigma_{y}$ their standard deviation. It is wellknown that the value of $a$ and $b$ which minimize the squared error between $y$ and $a x+b$ are given by:

$$
a=\frac{1}{n \sigma_{x}^{2}} \sum_{i}\left(x_{i}-\bar{x}\right)\left(y_{i}-\bar{y}\right) \quad \text { and } \quad b=\bar{y}-a \bar{x}
$$

The regression coefficient is given by $r^{2}=a \sigma_{x} / \sigma_{y}$. Now define the standard error of the residuals $S$ as:

$$
S^{2}=\frac{1}{n-2} \sum_{i}\left(y_{i}-a x_{i}-b\right)^{2}
$$

The standard error $e_{a}$ and $e_{b}$ on the regression coefficient $a$ and $b$ can be then calculated as follows:

$$
e_{a}=\frac{a}{\sqrt{n-2}} \sqrt{\frac{1}{r^{2}}-1} \quad \text { and } \quad e_{b}=S \sqrt{\frac{1}{n}+\frac{\bar{x}^{2}}{n \sigma_{x}^{2}}}
$$

Confidence intervals for $a$ and $b$ can then be taken as $\left[a-\alpha e_{a}, a+\alpha e_{a}\right]$ and $\left[b-\alpha e_{b}, b+\alpha e_{b}\right]$, with $\alpha$ a coefficient related to the level of confidence of the interval and the number of points $n . \alpha e_{a}$ and $\alpha e_{b}$ are therefore the uncertainties of the regression coefficients $a$ and $b$. Typically, when assuming normally distributed independent residuals and for a sufficient large value of $n$ (typically greater than 10), taking $\alpha=1$ yields a level of confidence of about $65 \%$, and $\alpha=2$ a level above $90 \%$. In this work, for simplicity the uncertainty is evaluated to be the standard error (which means $\alpha$ is taken to be equal to 1), hence the considered confidence level is about $65 \%$. 